\title{
Sustainable textile materials in interiors
}

\author{
A. Fathy \\ College of Fine Arts and Design, University of Sharjah, UAE
}

\begin{abstract}
Textiles that consume as few resources as possible, concerning both material use as well as energy needs, play an emerging role in sustainable interior design. As the textile industry works toward sustainability, the principle factors that have been addressed are related to ethical issues in production systems and ecomaterials. However, the majority of modern business models are mainly concerned with large production and sales volume. Furthermore, energy and resource consumption have increased to levels that reduce the benefits of technological development. Significant changes are needed in order to reach systematic transformations in production and consumption. This article discusses sustainable textile materials as a part of sustainability in interior design.

Keywords: sustainable textiles, interior design, sustainable interior design, textile industry, sustainability, interior textiles.
\end{abstract}

\section{Introduction}

A great percentage of energy is used to run buildings all over the world. In Switzerland, space- and water-heating in residential buildings account for one quarter of overall Swiss energy consumption [1]. In Belgium, $\mathrm{CO}_{2}$ emissions from interior heating increased by $11.6 \%$ between 1990 and 2005, with overall $\mathrm{CO}_{2}$ emissions from interior heating around $22 \%$ [2]. Large quantities of fossil fuels are consumed in generating the energy needed to maintain an ideal standard of living.

This situation calls for a reorientation of thought, particularly towards the structure of our built environment. Designers must exert a far more decisive influence on urban planning, building concepts, and construction components in order to achieve a reduction in energy use for building production and lifetime energy consumption. 
Textiles are one of the most widely used materials in many areas, including interior design. The application of textiles in interior environments can produce various results; an interior environment can be made light and soft, or colourful. Different individuals prefer different atmospheres, and thus require different ways of applying textiles. An important feature of textiles is that they are quite flexible [3]. Hence, sustainable textiles contribute directly to a sustainable interior environment.

The textile industry is one of the most important sectors for economic development in countries all over the world [4]. It has a heterogeneous structure with complex production chains and many different sub-sectors [5]. The textile industry is also known for its intensive resource usage in complex production processes [6] and high quantity of chemical consumption, especially in dyeing and finishing processes [7]. Specific consumption can vary depending on fibre type and applied technologies in textile production processes [8]. Thus, the main environmental concerns of the textile industry are wastewaters with high flow rates and pollutant loads [9]. Textile wastewaters contain surfactants, dyes, pigments, resins, chelating agents, dispersing agents, inorganic salts, heavy metals, and biocides, and are therefore heavily loaded with chemicals, colours, and salt [10]. Inadequately treated textile effluents are known to cause significant environmental problems in receiving waters [11]. High thermal energy requirements in production processes and intensive chemical usage that produce gaseous emissions and solid waste are other causes of pollution by the textile industry [12].

\section{Sustainability and interior textiles}

Sustainability is interpreted through various definitions. The World Commission on Environment and Development (WCED) [13] defines sustainable development as an approach to "meet the needs of the present without compromising the ability of future generations to meet their needs". The Global Development Research Centre (GDRC) [14] defines sustainable development as "maintaining a delicate balance between the human need to improve lifestyles and feeling of well-being on one hand, and preserving natural resources and ecosystems, on which we and future generations depend". The Environmental Protection Agency (EPA) [15] offers a definition centred on the balance of three principles: environmental sustainability, economic sustainability, and social sustainability. To increase the benefits of sustainable practices, these three sustainability principles should be maintained throughout the design [16]. Sustainable interior design should also integrate all systems and materials for "the purpose of minimizing negative impacts on the environment and occupants and maximizing positive impacts on environmental, economic, and social systems over the life cycle of a building" [17].

Sustainability is a multiphase term that applies to every stage of a textile's lifespan. It refers to managing waste and avoiding pollution, conserving resources, and utilizing materials and furnishings with renewable components. A sustainable environment employs furnishings from renewable resources with 
long lifespans and requiring minimal upkeep. Sustainable design also means the creation of healthy, clean environments for occupants. Further, a sustainable environment incorporates reuse and recycling to avoid waste and landfill buildup, which takes us full circle back to the goal of avoiding pollution.

According to the U.S. Green Building Council [18], the global built environment is growing three times faster than the population growth rate. Buildings have a huge impact on the resources of a finite earth, consuming 30 to $40 \%$ of all energy used and gobbling up as much as $30 \%$ of all raw materials produced annually [19]. Creating sustainable interiors includes specifying sustainable materials and products; improving indoor air quality, which enhances productivity as well as general health and wellbeing; extending textile lifespans; and enhancing resource efficiency through efforts to reduce, reuse, recycle, and repair. The result is not only the improvement of life in the built environment but, surprisingly often, substantial cost savings from conservation of energy and resources [20].

Textiles play a growing role in architecture toward these considerations. They impart a more flexible aspect to even the most rigid building materials. Constructions made of textiles are light and mostly translucent. Textiles are used for several purposes, the main ones being protection from the sun and rain. They can also let certain amounts of the sun pass through and illuminate the interior space with daylight. Further, textiles can be used for insulation against heat or noise when constructed of multi-layer elements, and can be used for parts of buildings roofs, facades, or interior components [19].

\subsection{Textiles in the Leadership in Energy and Environmental Design (LEED)}

The many design professionals who need assistance with green specification can turn to excellent resources such as the Leadership in Energy and Environmental Design Contract Interiors (LEED-CI) section of the LEED Green Building Rating System.

Based on well-founded scientific standards, LEED emphasizes strategies for sustainable site development, water savings, energy efficiency, materials selection, and indoor environmental quality. LEED recognizes achievements and promotes expertise in green building through a comprehensive system of project certification, professional accreditation, training, and practical resources.

In the United States, buildings use one-third of the total energy, two-thirds of the total electricity, and one-eighth of the total water consumed. Introduced in 1999, the LEED Green Building Rating System for New Construction (LEEDNC) has helped improve the quality of buildings and their impact on the environment, helping produce a sustainable community.

The component of LEED certification concerning textiles is found within the LEED-CI section of the Green Building Rating Systems, and applies to improvements of new or existing spaces. This section includes Credit 3.3 Resource Reuse; Credit 4.3 Low-Emitting Materials: Carpet Systems; and Credit 4.5 Low-Emitting Materials: Systems Furniture and Seating. Other sections are Credit 8.2-8.3 Daylight and Views [21]. 


\section{The textile supply chain}

Textile products typically pass through a complex life cycle, beginning with the production of raw materials required for manufacture. Figure 1 shows world production of textile fibre production. Textile supply chain is characterized by a huge range of processes, people, and places. All of these stages have a notable impact on the environment. The impact of textile production is particularly significant because textiles are so widely used [22]. A simple diagram of key stages in the textile product life cycle is shown in Figure 2.

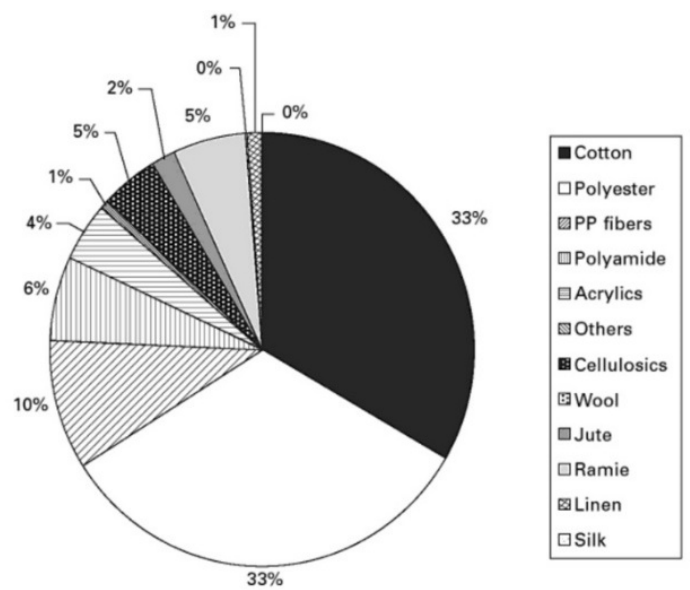

Figure 1: World production of textile fibre production.

\subsection{Natural fibres}

The first step in a product's life cycle is the production of raw materials. A basic distinction is made between natural and synthetic fibres. Natural fibres can be classified into plant fibres (such as cotton) and animal fibres (such as wool) [20]. As an example, Figure 3 shows key stages in the processing and production of cotton, the most widely used of the natural fibres. Although processes vary between fibres, cotton is a good example of the kind of environmental impact a natural fibre can have. Cultivation involves the preparation, planting, and tending of cotton plants. Resources involved include seed (which has its own resource requirements), water (for irrigation), pesticides and fertilizers (which again use resources in their own production), machinery (e.g., for irrigation, spraying, and harvesting), energy (e.g., to power the machinery), materials (e.g., packing materials for baling cotton), as well as labour. Other types of environmental impact include emissions and potential pollution (e.g., from the use of insecticides). 


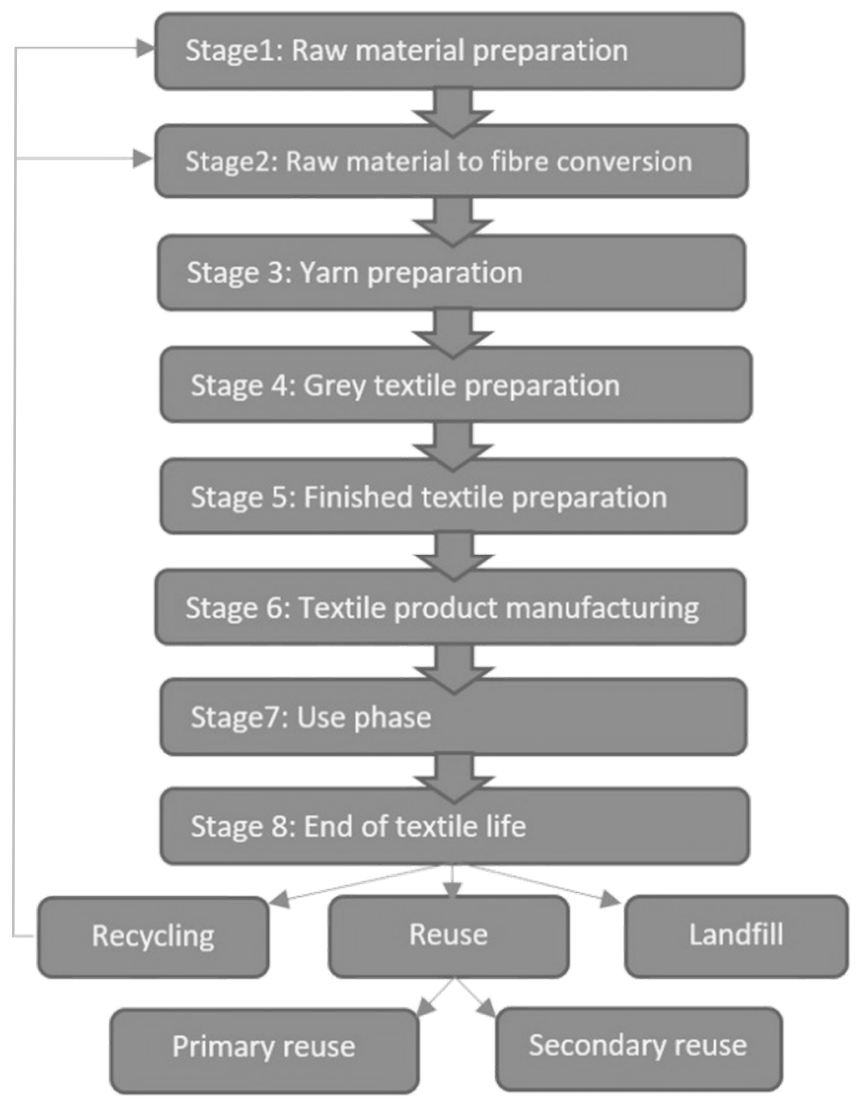

Figure 2: The textile product life cycle.

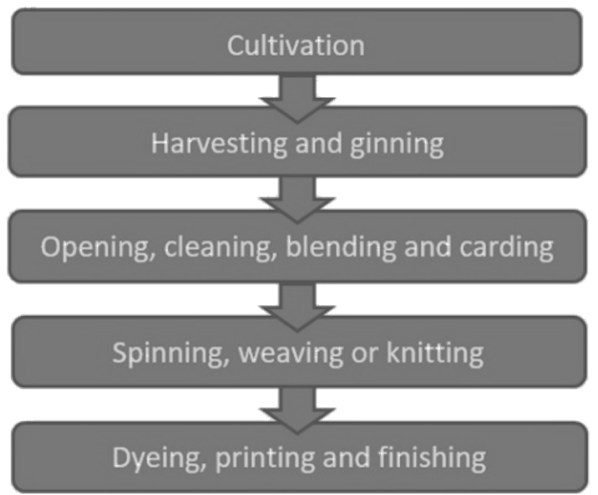

Figure 3: Key stages of cotton production. 
It has been estimated, for example, that cotton uses $2.5 \%$ of the world's cultivated land and $16 \%$ of the world's pesticides [23]. This has led to increased interest in growing organic cotton which avoids the use of synthetic fertilizers and pesticides, thus reducing overall resource and energy use, emissions, and pollution, as well as increasing biodiversity.

Once it has reached maturity, cotton must be harvested. The fibres are separated from the seed by a process called 'ginning' and packed together in bales to be transported to a processing plant. There, the cotton bales must be opened, the cotton fibres blended to achieve the desired quality, and finally they are cleaned and carded to get them ready for spinning and other processes [22].

Spinning, weaving, knitting, and other processes for fabric production require factory buildings (including humidification systems to create the right conditions for processing), spinning or other machinery, significant amounts of energy to run the machinery, as well as materials such as chemicals that improve fibres for processing (e.g., use of sizing materials to strengthen yarns for weaving), lubricants, and packaging. Processes such as spinning also produce noise, dust, fibre, and other types of waste. Studies show the environmental impact of both weaving and knitting are less extensive than spinning; likewise, it is assumed that knitting consumes less energy than either spinning or weaving [19].

Due to the chemicals and volumes of water required, dyeing has traditionally been a significant cause of pollution via wastewater disposal. Key finishing processes include:

- Singeing: passing fabrics over a flame that burns 'fuzz' off the surface to leave it looking smoother;

- Desizing: removal of sizing materials (used to strengthen yarns for weaving);

- Scouring: application of chemicals to remove unwanted residues (e.g., waxes) from natural fibres;

- Bleaching: application of chemicals to produce a whiter, more evenly coloured material for dyeing;

- Mercerising: the use of sodium hydroxide to swell fibres and improve their strength and appearance.

Many of these processes require subsequent washing and drying steps. Finishing processes involve the use of strong, potentially harmful chemicals as well as significant volumes of water, and generate a large amount of contaminated wastewater [22].

\subsection{Synthetic fibres}

The majority of synthetic fibres are polymer-based [20] as can be seen in figure 4 . One of the most widely used is polyester, which will be discussed here as an example. Figure 5 shows the key stages in the production of polyester. Polyester is made out of purified terephthalic acid, dimethyl terephthalate, and mono-ethylene glycol. These materials are all derived from crude oil. Extraction of crude oil requires very energy-intensive processes (e.g., drilling) with high emissions, as well as pollution risks. Refining requires large amounts of heat and 
other resources, generating significant emissions and waste. Production of resins used in polyester manufacturing requires further energy and resource inputs [22].

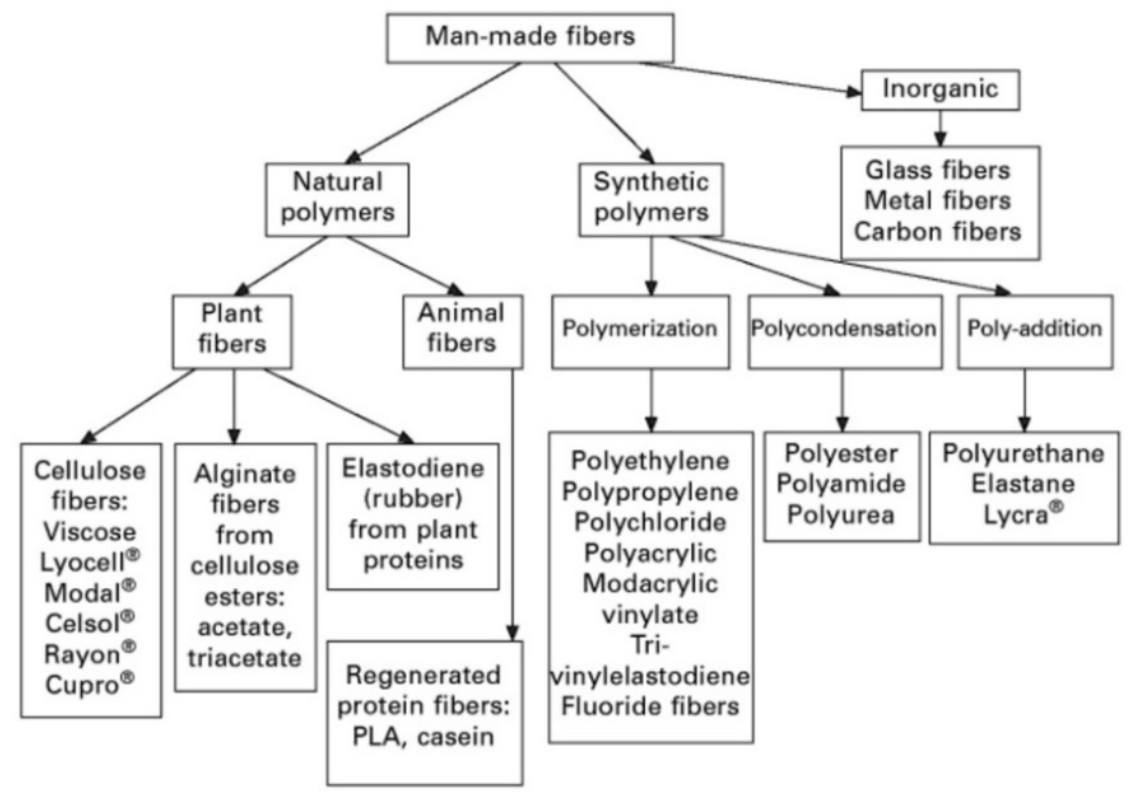

Figure 4: Man-made fibres according to their chemical structure.

The manufacturing of polyester fibres starts with producing a solid fibreforming material in the form of polymer chips. These chips are then converted into a spinning fluid using heat or a solvent. Typical spinning techniques include melt, wet, and dry spinning. All of these processes require significant amounts of energy and extensive use of chemicals, generating both emissions and waste.

It has been estimated that the energy required to produce polyester fibre can be as high as 125 megajoules per kilogram of fibre $(\mathrm{MJ} / \mathrm{kg})$. This can be compared to estimates of $55 \mathrm{MJ} / \mathrm{kg}$ for conventional cotton and as low as 15 $\mathrm{MJ} / \mathrm{kg}$ for organic cotton. Carbon dioxide emissions are also much higher for polyester. Polyester production generates volatile organic compounds, both carcinogenic and particularly damaging to the ozone layer, which potentially accelerates global warming [23].

There are some areas where polyester may have less environmental impact than a natural fibre such as cotton; for instance, it requires a more limited amount of water. Synthetic fibres may also need fewer finishing treatments than natural fibres. However, fibres like polyester will not accept natural dyes, relying instead on more environmentally damaging synthetic dyes. While synthetic fibres may be more durable than natural fibres, thereby extending the lifespan of their fabrics, they are not completely biodegradable, making waste disposal a major problem [22]. 


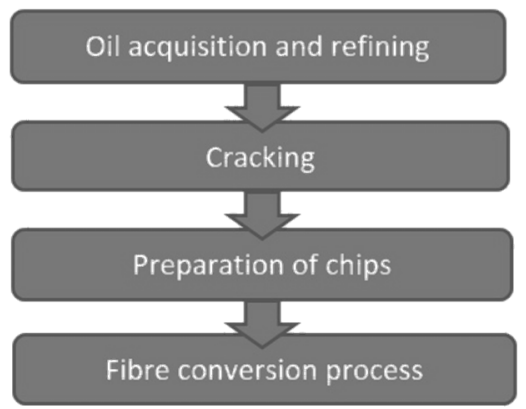

Figure 5: Key stages in the production of polyester.

\subsection{Assessing the environmental impact of the textile supply chain}

The production of textile products involves a complex supply chain with a broad range of environmental effects, including:

- Use of natural resources;

- The need for potentially harmful chemicals for raw material production and processing;

- Energy use for processing;

- Emissions and effluents from processing, transport, and retail operations;

- Large volumes of waste products requiring disposal

Defining and quantifying these impacts, identifying particular problem areas for improvement, and making sensible comparisons between different fibres and processes is a huge challenge [24].

The best established methodology for assessing the environmental impact of textiles and other products is Life Cycle Assessment (LCA). LCA evaluates the range of impact that a product has on the environment, from raw material production all the way to the disposal of the final product at the end of its useful life. The International Standards Organization (ISO) [25] defines LCA as a "compilation and evaluation of the inputs, outputs, and the potential environmental impacts of a product system throughout its life cycle". LCA also provides the basis for eco-labelling schemes designed to encourage consumers to select more environmental-friendly products [26].

The key steps in LCA methodology are:

- Goal and scope definition;

- Inventory analysis;

- Impact assessment;

- Interpretation.

Goal and scope definition involves setting objectives for the assessment. It requires a definition of the product to be studied, the key production processes to be analysed, and the type of environmental impacts to be measured. A key aspect is the 'functional unit', which defines precisely what is being assessed. In this case, both the materials and the estimated amount of use are clearly defined [20]. 
Inventory analysis involves constructing a flow chart of the overall production process and breaking it down into separate unit processes. This stage requires a data collection plan that typically involves data related directly to the production of the textile as well as indirect data, which includes inputs and outputs related to the materials and processes that make production possible, such as fertilizers and pesticides for cultivating crops like cotton. Figure 6 shows potential negative impact on environment and people caused by application of pesticides.

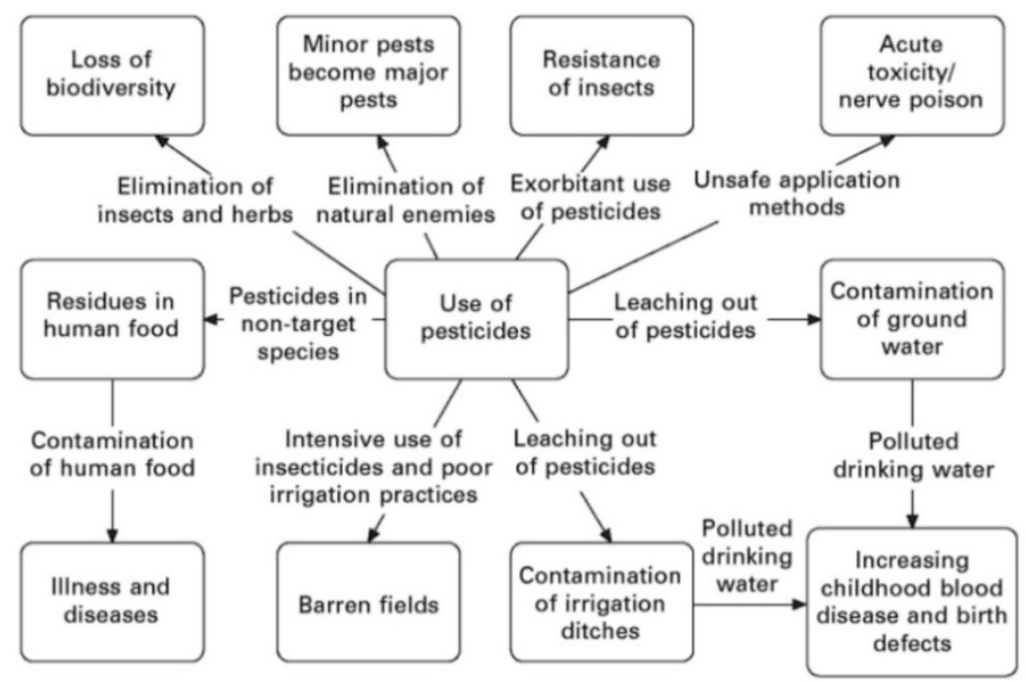

Figure 6: Potential negative impact on environment and people caused by application of pesticides.

Impact assessment defines the key categories of environmental impact, the key units of measurement, and sets out calculations of various inputs and outputs. Finally, the interpretation stage sets out the key results and recommendations, outlining unit processes with the greatest environmental impact and what might need to be done in order to reduce that impact [24].

\subsection{Minimizing the environmental impact of the textile supply chain}

The use of methods such as LCA makes it easier to identify which stages of a textile's life cycle have the greatest environmental impact. A designer must work within the brief set by the company developing a new product range. It must be cost-effective and easy to manufacture. These requirements will determine the choice of fabrics, colours, patterns, manufacturing methods, finishes, and accessories such as fastenings. It may also determine where a product will be manufactured, which may further limit choice [19].

Owing to these constraints, designers need to take a life cycle approach to design; that is, they must think through the potential impact of their design from 
raw material production all the way to the disposal of the product. A designer should be aware of the relative environmental impacts of different textile fibres, with regard to their method of production, durability, and recyclability. Durability can be important in that a product with a long lifespan may have far less overall environmental impact than a series of more disposable items. Designers should also have an understanding of the environmental profile of different manufacturing processes, as well as an awareness of how customers are likely to treat their product (e.g., washing and drying, which has a particularly significant environmental impact) [20].

Within any design brief or project, it is ideal to incorporate sustainability into the heart of the design and brand identity, as companies like From Somewhere and Junky Styling have done. Other options for more environmental-friendly design include:

- Design for disassembly (e.g., using biodegradable fabrics);

- Design for durability (e.g., modular solutions);

- Design using recycled materials.

Designers can use their designs to encourage greater environmental awareness amongst customers and create an eco-friendly dimension to an existing brand, helping to differentiate it from competitors.

A basic but significant contribution to reducing the environmental impact of manufacturing, while reducing costs and increasing overall quality, is to use "best available technology" as well as implement good process control in conventional production, including [24]:

- Selection of machinery with good energy efficiency and service life;

- Good maintenance of process machinery;

- Setting objectives for energy use, levels of waste, and emissions;

- Precise measurement and control of materials and energy consumption, as well as emissions and waste;

- Closed-loop production systems (e.g., recycling and reuse of water)

Effective labelling and marketing by retailers can advertise these benefits to consumers as cost-effective, convenient, and contributing to sustainability.

Within the constraints of cost, functionality, and product positioning in the market place, both designers and manufacturers can choose between different materials and technologies on the basis of sustainability. It may be possible, for example, to select organically grown cotton or a biodegradable synthetic fibre such as PHA (polyhydroxyalkanoate). Similarly, it may be possible to use a natural rather than synthetic dye, or select more environmental-friendly technologies such as biotechnologies (e.g., using enzymes) and plasma technologies in finishing processes [26].

\section{Conclusion}

Designers' jobs have increased in complexity. Modern products need to be beautiful, hold up to high design standards, and be suitable for their end-users and the market. Today, designers must also consider the environmental consequences of the manufacture and use of products they specify; in fact, 
everyone who creates and uses materials should strive to understand their environmental impacts. Our planet will be well served if all designers, clients, and manufacturers are aware of the environmental impact of their projects and of the choices that lead to sustainable solutions [19].

This paper addressed the issue of how the manufacturing and use of textiles affects both the built environment and the natural environment. Interior textiles play a major role in the updating, refurbishing, and renewal of interiors, even when the interior architecture remains the same. This is problematic in matters of sustainability [20]. Sustainability in textiles is essential as fabric is one of the most common materials in interior environments. Increasing textile sustainability should in turn help promote sustainable interior design.

This paper also discussed the textile supply chain and its impact on the environment, followed by ways to assess and minimize such impact. These were examined in an effort to enlighten and inspire a wide spectrum of textile use for interior design, especially targeting designers, manufacturers, and those engaging in creative textile selection for various interior design applications.

Through a better understanding of what underpins ethical and sustainable textile issues, designers should become multi-dimensional and more informed in their work, with the potential to innovate and influence.

\section{References}

[1] Kost, M., Langfristige Energieverbrauchs- und $\mathrm{CO}_{2}$ - Reduktionspotentiale im Wohngebäudeordner Schweiz, ETH Zürich: Zürich, 2006.

[2] Hubert, A., President of the International Polar Foundation, in the conference Du bois dans les glaces éternelles, Luxembourg, 2008.

[3] Lee, K., Fabric Styles, Design Media Publishing ltd: Hong Kong, 2011.

[4] Souza, A.A.U., Melo, A.R., Pessoa, F.L.P. \& Souza, S.M.A.G.U., The modified water source diagram method applied to reuse of textile industry continuous washing water, Resources, Conservation and Recycling, 54(12), pp. 1405-1411, 2010.

[5] European Commission (EC), Integrated Pollution Prevention and Control (IPPC) Reference Document on Best Available Techniques for the Textile Industry (BREF), The European IPPC Bureau: Seville, Spain, 2003.

[6] Kocabas, A.M., Yukseler, H., Dilek, F.B. \& Yetis, U., Adoption of European Union's IPPC Directive to a textile mill: analysis of water and energy consumption, Journal of Environmental Management, 91(1), pp. 102-113, 2009.

[7] Verma, A.K., Dash, R.R. \& Bhunia, P., A review on chemical coagulation/flocculation technologies for removal of colour from textile wastewaters, Journal of Environmental Management, 93(1), pp. 154-168, 2012.

[8] Brik, M., Schoeberl, P., Chamam, B., Braun, R., Fuchs, W., Advanced treatment of textile wastewater towards reuse using a membrane bioreactor, Process Biochemistry, 41(8), pp. 1751-1757, 2006. 
[9] Moore, S.B. \& Ausley, L.W., Systems thinking and green chemistry in the textile industry: concepts, technologies and benefits, Journal of Cleaner Production, 12(6), pp. 585-601, 2004.

[10] Dasgupta, J., Sikder, J., Chakraborty, S., Curcio, S. \& Drioli, E., Remediation of textile effluents by membrane based treatment techniques: a state of the art review, Journal of Environmental Management, (147), pp. 55-72, 2015.

[11] Reddy, N., Chen, L., Zhang, Y. \& Yang, Y., Reducing environmental pollution of the textile industry using keratin as alternative sizing agent to poly (vinyl alcohol), Journal of Cleaner Production, 2014.

[12] Hasanbeigi, A., Hasanbadi, A. \& Abdorrazzaghi, M., Comparison analysis of energy intensive for five major sub-sectors of the Textile Industry in Iran, Journal of Cleaner Production, 23(1), pp. 186-194, 2012.

[13] World Commission on Environment and Development (WCED), Our common future, The Brundtland Report, Oxford University Press: New York City, 1987.

[14] Global Development Research Center (GDRC), (2008), Definition of sustainable development, 2008. http://www.gdrc.org/sustdev/ definitions.html

[15] Environmental Protection Agency (EPA), Technology for a sustainable environment, 2012. http://www.epa.gov/ncer/science/tse/

[16] Bonda, P. \& Sosnowchik, K., Sustainable Commercial Interiors, John Wiley \& Sons: Hoboken, NJ, USA, 2007.

[17] Kang, M. \& Guerin, D.A., The state of environmentally sustainable interior design practice, American Journal of Environmental Sciences, 5(2), pp. 179-186, 2009.

[18] US green building council. Online. www.usgbc.org

[19] Yates, M., Fabrics: A Guide for Interior Designers and Architects, W.W. Norton \& Company Inc.: New York City, 2002.

[20] Nileson, K.J., Interior Textiles, John Wiley: Hoboken, NJ, USA, 2007.

[21] Leadership in Energy and Environmental Design (LEED), LEED Certification Policy Manual, US Green Building Council Online. www.usgbc.org

[22] Jackman, D., Dixon, M. \& Condra, J., The Guide to Textiles for Interiors, Portage \& Main Press: Winnipeg, MB, Canada, 2003.

[23] Muthu, S., Assessing the environmental impact of textiles and the clothing supply chain. Woodhead Publishing Limited: Cambridge, UK, 2014.

[24] Tobler-Rohr, M., Handbook of sustainable textile production, Woodhead Publishing Limited: Cambridge, UK, 2011.

[25] international Standards organization (ISO), Environmental management Life cycle assessment - Principles and framework Online. www.iso.org/ iso/home/store/catalogue tc/catalogue detail.htm?csnumber $=37456$

[26] Blackburn, R., Sustainable textiles: Life cycle and environmental impact, Woodhead Publishing Limited: Cambridge, UK, 2009. 